\title{
Internal audit in a microbiology laboratory
}

\author{
A J Mifsud, M S Shafi
}

\begin{abstract}
Aim-To set up a programme of internal laboratory audit in a medical microbiology laboratory.

Methods-A model of laboratory based process audit is described. Laboratory activities were examined in turn by specimen type. Standards were set using laboratory standard operating procedures; practice was observed using a purpose designed questionnaire and the data were analysed by computer; performance was assessed at laboratory audit meetings; and the audit circle was closed by re-auditing topics after an interval.

Results-Improvements in performance scores (objective measures) and in staff morale (subjective impression) were observed.

Conclusions-This model of process audit could be applied, with amendments to take local practice into account, in any microbiology laboratory.

(f Clin Pathol 1995;48:560-563)
\end{abstract}

Keywords: Clinical audit, quality assurance, hospital laboratories, microbiology techniques.

The fundamental role of a hospital's microbiology department is to support and assist clinicians in the management of patients suspected of suffering from infection.

Clinicians rightly expect a high quality of service from the laboratories. It is the responsibility of the head of each department to ensure that mechanisms are in place that will lead to the delivery of such a quality service. While microbiologists, in common with all other doctors, consider high quality to be an integral part of their work, the government and consumers expect this to be quantified. ${ }^{1}$

The presence of a laboratory quality assurance programme is part of the means by which these groups can be satisfied. "Quality assurance" must not be confused with "quality control". While the latter includes measures designed to ensure the reliability of laboratory data, such records and controls do not necessarily assure quality as they do not normally cover many factors critical to the delivery of a quality service (for example, specimen mislabelling, transportation delays, appropriate choice of tests). Quality assurance has been defined as a set of investigations which inspires confidence in the final results. ${ }^{2}$ The implementation of quality assurance programme depends on an ongoing appraisal of the contribution of laboratory results to high quality patient care. ${ }^{3}$

It is generally accepted that audit is a necessary prerequisite to a successful quality as- surance programme. Indeed the United Kingdom government has explicitly stated that all hospital doctors are expected to participate in audit ${ }^{4}$ and their initiative has been widely welcomed within the medical profession, including the Royal College of Pathologists, ${ }^{5}$ and by the Institute of Biomedical Science. Furthermore, the medical royal colleges and faculties increasingly require evidence of audit before accrediting posts for specialist training. ${ }^{6}$

Audit, in the clinical context, has been defined as "the systematic, critical analysis of the quality of medical care including the procedures used for diagnosis and treatment, the use of resources and the resulting outcome and quality of life for the patient". ${ }^{1}$ Audit of the laboratory aspects of microbiology comes under the ambit of clinical audit, as the activities involved are carried out by medical and other hospital staff, as opposed to medical audit, which is concerned with activities initiated by medical staff alone. ${ }^{6}$ While in its earlier directives, the Department of Health's main thrust was to introduce medically led audit into health care, more recently the importance and benefits of a multiprofessional approach to audit have been emphasised. ${ }^{7}$

It is possible to audit virtually any activity. Some examples are given in the table. For instance, the Audit Commission has reviewed the management of laboratories in a cross section of the NHS. ${ }^{8}$ Looked at from another viewpoint, audit may be concerned with various facets of activity. ${ }^{9}$ These include (1) structure audit, which examines the resources (financial, physical, human, etc) and other aspects of the

\begin{tabular}{|c|c|}
\hline Examples of types of a & \\
\hline Financial and efficiency & $\begin{array}{l}\text { - Cost per specimen } \\
\text { - Staff utilisation factor }\end{array}$ \\
\hline Personnel & $\begin{array}{l}\text { - Staff turnover rates } \\
\text { - Absenteeism rates }\end{array}$ \\
\hline Organisational & - Management structure \\
\hline Safety & \\
\hline Clerical & $\begin{array}{l}\text { - Accuracy of data entry } \\
\text { - Completeness of data } \\
\text { retrieval }\end{array}$ \\
\hline Technical & $\begin{array}{l}\text { - Documentation } \\
\text { - Adherence to standard } \\
\text { operating procedures } \\
\text { - Proficiency testing results } \\
\text { - Turnaround times }\end{array}$ \\
\hline Medical & $\begin{array}{l}\text { - Consistency of clinical } \\
\text { advice } \\
\text { - Clinicans' compliance with } \\
\text { microbiologists' } \\
\text { recommendations }\end{array}$ \\
\hline Infection control & $\begin{array}{l}\text { - Hospital acquired infection } \\
\text { rates } \\
\text { - Compliance with MRSA } \\
\text { protocols }\end{array}$ \\
\hline
\end{tabular} \\ of Microbiology \\ and Public Health \\ Central Middlesex \\ Acton Lane. \\ London NW10 7NS \\ 3 November 1994
}


environment (for example, laboratory protocols); (2) process audit, which deals with the activity within the laboratory, including adherence to the aforementioned protocols, achievement of (internal) performance indicators, etc; and (3) outcome audit, which is concerned with the impact of any activity on the patient and may be viewed as the final arbiter.

The Department of Health has made various recommendations regarding the practice of medical audit. ${ }^{10}$ They suggest that at local level, a practical method of audit as applied to "diagnostic departments" would entail the retrospective review of all aspects of the laboratory's work, including diagnostic accuracy, timeliness of reporting, and record keeping, as well as a review of contributions to general standards of patient care, such as ensuring the appropriate use of investigations. They state that the interpretative work must also be audited, but accept that it may not be best for this to be carried out at individual unit level, and that a regional approach might be more appropriate. Indeed, this is the recommendation of the working party of the Clinical Services Committee of the Association of Medical Microbiologists. ${ }^{11}$ The Department of Health recommends that audit meetings should be held regularly (at least monthly), be attended by all relevant medical staff, be prepared in advance, and be fully documented, with reports sent to the local medical audit coordinator. Recommendations for corrective action have to be conveyed to management or to other appropriate bodies where deficiencies in service have been identified.

For an audit programme to be effective it has to satisfy several criteria. According to the Department of Health, ${ }^{7}$ the fundamental principles of audit (amended to the situation in a diagnostic department) are that it should: be professionally led; be seen as an educational process; form part of routine laboratory and clinical practice; be based on the setting of standards; generate results that can be used to improve outcome of quality care; involve management in both the process and outcome of audit; be confidential at the individual patient/clinician/Medical Laboratory Scientific Officer (MLSO) level; and be informed by the views of patients/clients. Therefore, it is important that any newly set up audit, or indeed any existing programme, must fulfil these points.

\section{Local experience of audit}

Audit activities at Central Middlesex Public Health Laboratory are undertaken at two separate fora: the examination of "core" standard operating procedures at a regional level by peer consensus review; and the evaluation of internal laboratory performance using (among other standards) the aforementioned standard operating procedures locally. The standard operating procedures consist of a collection of documents which describe in detail all aspects of the handling and processing of specimens, from sample collection to result reporting. There is a regular local review of these pro- cedures to take into account service improvements, advances in the practice of clinical pathology, and the consensus view of microbiologists in the Regional Microbiology Association Audit Group. In this paper the activities undertaken at regional level will not be discussed further.

At laboratory level, audit activities are organised by the audit steering group, an informal grouping of medical and MLSO staff appointed by the laboratory director. It was felt that audit of process was the most practical, as many aspects of both structure and outcome would be best tackled in either peer review or in cooperation with other clinical specialists. It was therefore decided to undertake an in-depth retrospective examination of the whole of specimen processing, starting from specimen collection and ending with result reporting.

\section{SETTING STANDARDS}

In any audit programme, the first stage consists of setting standards. This can often be difficult. For instance, while it is relatively straightforward to estimate desirable turnaround times, it can be difficult to assess the percentage of cases in which this "standard" ought to be achieved. For most activities, the laboratory standard operating procedures were used as a standard. When a standard is not available, estimates of achievable performance are made by consensus among the members of the audit steering group.

\section{OBSERVING PRACTICE}

A regular rolling programme of audit was drawn up, each laboratory section or "bench" being examined in turn. Meetings were held on a monthly basis during academic term time. Most specimen types were audited on at least one occasion.

It was decided to measure practice using random samples of laboratory specimens submitted to each bench. A questionnaire was designed for the purpose (see the appendix). This was designed around the work flow and practices of the bacteriology section at Central Middlesex Public Health Laboratory. The precise contents of the questionnaire could be amended to take into account the practices of individual laboratories. In order to maximise objectivity and to facilitate data processing, questions were set in a way which required a numerical or yes/no response. This enabled the questionnaire to be completed by any member of the laboratory staff. In addition, an amended version of the questionnaire was prepared for the virology section. This was because a large proportion of requests for virological investigations are derived from other hospital microbiology departments, and the laboratory methodology of serological tests is fundamentally different from bacteriological investigations.

Preparations for each audit session were led by a member of the audit steering group, usually a senior registrar, in conjunction with MLSOs (usually two or three at each session, usually grade 1 or 2 ). 
For most audit sessions, 100 requests for the specimen type to be audited were examined. These were selected randomly from recent requests on the pathology computer system using a purpose written program. As it was felt that positive samples would be more likely to give rise to problems, the selection system was weighted in favour of "positives" to give 50 each of positive and negative reports.

The questionnaires were completed, and the results entered into an integrated spreadsheet/ database computer package (Lotus Symphony 2.2). Tabulated summaries of the findings were prepared.

\section{ASSESSING PERFORMANCE}

The results were presented at the audit session. All members of staff were expected to attend. The findings were discussed where the measured performance was reviewed and an explanation for any deficiencies sought. If it was felt that suboptimal performance was due to a deficiency in the laboratory methods, these would be reviewed at the earliest opportunity. If, on the other hand, any deficiencies were considered to be "human error", then the possibility of introducing checks or fail safe methods was investigated.

\section{CLOSING THE CIRCLE}

The objective of audit is to improve the quality of laboratory work. Therefore, revisiting previously examined areas of activity is an integral part of the audit cycle. This was done by reauditing specimen types or particular activities, for example clerical aspects of laboratory work.

\section{Outcome of first 18 months of audit programme}

During this period, substantial improvements were seen in several laboratory activities, including the internal documentation of laboratory processing, clerical error rates, and turn around times.

The audit programme has been very well accepted by all levels of staff. Attendance at audit meetings has been uniformly high. It has led to a greater ownership of work, and staff have been gratified to see improvements in scores.

More recently, a multidisciplinary approach to audit has been tried. Whenever the audit topic concerned a specific clinical specialty, members of the relevant team would be invited to attend and contribute to the sessions. This was piloted successfully in a syphilis serology audit session, when physicians and nurses from the genito-urinary clinic were asked to give the consumer's opinion of the service offered.

The process audit described was set up around the custom and practice at Central Middlesex Public Health Laboratory. However, it could be easily amended to suit local practice in any laboratory.

We thank Professor C Roberts for helpful advice.

\section{Appendix}

Central Middlesex Public Health Laboratory audit questionnaire

\section{REQUEST FORM}

1. Is laboratory card available?

Have the following been completed on request form?

2. Hospital no

3. Name

4. DOB/Age

5, Location (Ward, A/E, etc)

6. Requester (Consultant, GP, etc)

7. Clinical data

8. Specimen date

9. Specimen time

Do specimen label details correctly match information on request form, with respect to:

10.

11.

Name?

Date?

Specimen type?

\section{SPECIMEN DELIVERY}

13. Was this an ON CALL request?

14. Is collection date on form the same as the laboratory reception date stamp?

\section{SPECIMEN REJECTION}

15. Was specimen rejected before processing?

16. If $15=$ YES, was it because of:

(a) mislabelling (incorrect name)

(b) no labelling (no name)

(c) leaking

(d) unsuitable for processing (eg saliva)

17. Was requester notified as early as possible that specimen had been rejected?

\section{RECEPTION/CLERICAL}

18. Is "Collection date" on laboratory computer correct?

19. Is "Received date" on laboratory computer correct?

20. Are other details on laboratory computer correct?

\section{LABORATORY METHODS}

21. Was the whole of the laboratory work process clear from laboratory work card?

22. Was specimen described macroscopically?

23. Was description consistent with subsequent findings?

24. Was microscopy performed?

25. Was microscopy result consistent with subsequent findings?

26. Were additional tests indicated on Day 1 (eg direct sensitivities)?

27. If $26=$ YES, were they done?

28. Were plates (including discs) set up according to laboratory method (as in method book)?

29. If $28=\mathrm{NO}$, were plates missed out?

$30 . \quad$ or were extra plates put up?

31. Is there evidence of incorrect incubation conditions?

32. Was identification work needed?

33. If $32=\mathrm{YES}$, on how many organisms?

34. Were all correct tests performed?

35. Was(were) result(s) obtained first time?
(lines $\mathrm{a}-\mathrm{d}$ for separate isolates)

(a)

(b)

(c) 
36. If $35=\mathrm{NO}$, how many attempts were needed?<smiles>[111In]</smiles>

37. Was susceptibility testing performed?

38. If $37=\mathrm{YES}$, was a repeat necessary?

39. If $38=Y E S$, how many attempts were needed?

40. Were any extra tests or investigations requested but not performed?

\section{REPORTING}

41. Was specimen notified as "Urgent"?

42. If $41=$ YES, was result telephoned?

43. Was report clerically correct?

44. Was report issued in a timely manner?

45. If $\mathbf{4 4}=\mathrm{NO}$, how long was delay?

Completion instructions: Yes $=1$, No $=0$, Not applicable $=$ NA.
1 Department of Health. Working for patients: medical audit. Working Paper 6. London: HMSO, 1989.

2 Kilshaw D Ouality assurance in clinical laboratories. IMLS Gazette 1991;35:253-5.

3 Manuselis G, Rausch M, Wilson P. Quality assurance in clinical microbiology. Clin Lab Sci 1989;2:34-6.

4 Department of Health. Working for patients. London: HMSO, 1989.

5 Royal College of Pathologists. Comments of the Royal College of Pathologists on the White Paper "Working for Patients" and the associated working papers for England. Bull $R$ Coll Pathol 1989;67:2-3.

6 Shaw $C D$, Costain DW. Guidelines for medical audit: seven principles. BMF 1989;299:498-9.

7 Department of Health. Meeting and improving standards in health care - a policy statement on the development of clinical audit. $\mathrm{EL}(93) 59,1993$.

8 Audit Commission. National Health Service Report No. 2. The pathology services: a management review. London: HMSO, 1991.

9 Farrington M. Medical audit in clinical microbiology in the United Kigdom. Rev Med Microbiol 1992;3:104-11.

10 Department of Health. The quality of Medical care: report of the Standing Medical Advisory Committee. London: HMSO, 1990.

11 Association of Medical Microbiologists. Medical microbiological audit. Report of a Working Part of the Clinical Services Committee of the Association of Medical MiServices Committee of the
crobiologists, January 1992. 